\title{
Autogenous fecal peritonitis in Wistar rats with permanent bilateral carotid occlusion. Morbidity, mortality and microbiological response ${ }^{1}$
}

\author{
Diego Nery Benevides Gadelha ${ }^{\mathrm{I}}$, Maria Cecília Santos Cavalcanti Melo"I, Thárcia Kiara Beserra Oliveira ${ }^{\mathrm{III}}$, Carlos Teixeira \\ Brandt $^{\mathrm{IV}}$
}

${ }^{\mathrm{I}}$ Fellow PhD degree, Postgraduate Program in Surgery, Health Sciences Center, UFPE. Associate Professor, Department of Ophthalmology, Medical Sciences Faculty of Campina Grande (FCM-CG), Campina Grande-PB, Brazil. Acquisition and interpretation of data, manuscript writing.

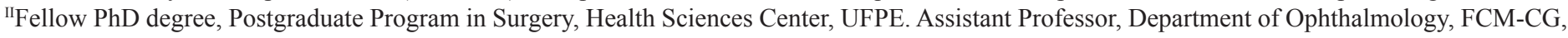
Campina Grande-PB, Brazil. Manuscript writing, critical revision.

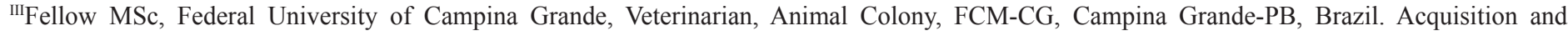
interpretation of data.

${ }^{\text {IV }}$ PhD, Head, Scientific Methodology and Pediatric Surgery, UFPE, Pernambuco, Brazil. Scientific and intellectual content of the study, interpretation of data, manuscript writing, critical revision.

\section{ABSTRACT}

PURPOSE: To investigate morbidity, mortality and microbiological response to fecal peritonitis induced in Wistar rats with permanent bilateral carotid ligation (PBCL).

METHODS: Fecal peritonitis was induced in 30 rats, with 10 animals in each group: Group1 - normal young animals; Group2 - normal mature animals; and Group3 - rats with PBCL after four months postoperative follow-up. Peritonitis was induced with $10 \%$ stool suspension. Morbidity and mortality were evaluated. The survival animals after seven days were euthanized for tests. For microbiological studies blood were collected from the carotids and right ventricle; and fragments of lung and peritoneum.

RESULTS: The morbidity and mortality of young animals were significantly lower than in mature animals with and without PBCL. There was no difference in morbidity and mortality among mature rats with and without PBCL. The diversity of microorganisms producing septicemia was similar to native micro biota of the large bowel.

CONCLUSIONS: The immune response was more efficient in young animals, represented by significant less morbidity and no natural mortality. PBLC did not affect morbidity and mortality in mature rats. The immune response to fecal peritonitis has age as an independent predictor.

Key words: Peritonitis. Hypoxia-Ischemia, Brain. Carotid Arteries. Microbiology. Immune System Disorders. Rats. 


\section{Introduction}

Sepsis remains a major cause of morbidity and mortality in elderly ${ }^{1}$, particularly if they undergo intra-abdominal surgery and stay in intensive therapy unit ${ }^{2,3}$.

The aging populations, the emergence of multiply resistant micro-organisms, the increasing use of invasive techniques, besides the increase in surgical procedures are among the factors that may explain the increased prevalence of septicemia, with peak usually occurring on the sixth decade ${ }^{4}$.

The elderly person is more susceptible to infection due to physiological changes of aging, decline in immune response and the presence of concomitant diseases. The declines in the function of $\mathrm{T}$ lymphocytes and cellular immunity and decrease the production of antibodies for immunization are extrinsic immunological changes that may enhance vulnerability to infection. The presence of diabetes mellitus, dementia, cerebrovascular disease, peripheral vascular disease and chronic obstructive pulmonary events are often found in the elderly that predisposes infections ${ }^{5}$.

Chronic encephalic hypoxemia in rats can be achieved by permanent bilateral carotid ligation (PBCL), which generates chronic moderate hypoglycemia that is associated with ageing and dementia, besides neurocognitive impairment and systemic reactions such as sympathetic nervous system reactions, immune cellular suppression, and opportunity for spontaneous bacterial infections ${ }^{6-8}$.

Sepsis in animals is a form of mimicking human disease, allowing translational research improving the medical care ${ }^{9-14}$.

There are no studies on peritonitis in rats with brain chronic hypoxemia due to PBCL; furthermore, it is not known that neurocognitive senescence is associated with immune senescence and severe infections ${ }^{15}$.

The purpose of the study was to investigate the morbidity and mortality; and also the microbiological response to sepsis due to fecal peritonitis in Wistar rats with PBCL comparing with young and mature control rats.

\section{Methods}

The study was approved by the Ethics Committee for Animal Research (CEUA/CESED/Campina Grande).

It was included 30 Wistar male rats (Rattus Novergicus Albinus Rodentia Mammalia), without any disease that could impair the brain oxygenation. All animals were born at the animal house of the Institution (FCM-CG). Group 1 - young rats with ages around three months, weighing from 230 to 330 grams; Group 2
- control mature rats with ages around 15 months, weighing from 320 to 570 grams, and Group 3 - mature rats with ages around 9 months, weighing from 390 to 550 grams with PBLC, with an average postoperative follow-up of four months.

Cerebral hypoperfusion was induced using PBCL. The animals were anesthetized with ketamine hydrochloride $(50 \mathrm{mg} /$ $\mathrm{kg}$ ) and xylazine $(10 \mathrm{mg} / \mathrm{kg})$. Through an incision in the midline of the ventral neck, the anatomic vascular-nervous bundle (vagus nerves and carotid arteries) were exposed. These structures were carefully separated and carotid permanently connected with nylon 4-0, approximately $8-10 \mathrm{~mm}$ below its origin.

Peritonitis was induced by intra-peritoneal inoculation of a $10 \%$ suspension of autogenous feces. Two grams of stools were collected for each own individually rat and dissolved in $20 \mathrm{ml}$ of $0.9 \%$ saline solution. This mixture was homogenized and filtered through gauze in order to remove large particles. It was injected $5 \mathrm{ml} / \mathrm{kg}$ of the suspension in the intra-peritoneal cavity, in the left iliac quadrant, using a $30 \times 12 \mathrm{~mm}$ needle. The rats had to have regular bowel habits and no macroscopic feces changes (blood, mucus or pus).

The animals were observed, by the veterinary, as regard to: activity, body temperature, respiratory rate and hair status, with the goal of obtaining signs of serious infection. Agonizing rats in the first 48 hours after fecal peritonitis induction were euthanized to collect blood from the right ventricle and carotid; and also peritoneum and lung fragments. Animals that survived the first 48 hours; and maintained well, were euthanized eight days after the induction of peritonitis for collecting the same materials. Between 48 hours and eight days any rat with clinical and hemodynamic instability with signs of marked respiratory distress, and pillage erection or mucous and serous-bloody secretion from the nose was euthanized for collection of various tissues and blood samples for microbiological analysis

The animals for the material collection of study were anesthetized with ketamine hydrochloride $(50 \mathrm{mg} / \mathrm{kg})$ and xylazine $(10 \mathrm{mg} / \mathrm{kg})$. Puncture was performed in the heart right ventricle with a $30 \times 15 \mathrm{~mm}$ needle and aspirate $2 \mathrm{ml}$ of blood. One milliliter of aspirate was discarded and one injected into the blood culture (Hemocult Pediatric Laborclin). The same procedure was performed for the carotid artery. Subsequently, abdominal midline incision was performed allowing access to the peritoneal cavity and a peritoneum fragment was removed and packed in a sterile Petri dish in order to facilitate the weighing of the same.

Abdominal cavity was inspected for: abscess identification; adhesions; and macroscopic infection signs like pus inside or in the solid organs. Photos were taken for documentation. 
Finally, the thorax was open and a lung fragment was taken. The tissues were placed into a sterile Petri dish for weighing in a scale Digimed, KN300, followed maceration in $1 \mathrm{ml}$ sterile saline solution with glass stick. One milliliter of this solution was sent for microbiology lab.

The blood culture vials and solution aspirate obtained from the peritoneum and lung were sent to the microbiological lab and were incubated at $35 \pm 2{ }^{\circ} \mathrm{C}$ after $24 \mathrm{~h}$ and cultivated in agar blood. The bacterioscopy was done by Gram. When the bacterioscopic exam was positive, it was followed by biochemical identification; if not the sample returned to the oven at $35 \pm 2{ }^{\circ} \mathrm{C}$ in $\mathrm{CO}_{2}$. After $48 \mathrm{~h}$, it was again cultivated in blood agar for seven days, and then a drop was cultivated in agar chocolate. If positive the case it was sent for final identification.

The solutions prepared from the lung and peritoneum fragments, as well as of positive blood cultures were taken with the aid of a platinum loop calibrated at a rate of $100 \mathrm{~mL}$ of solution by rifling and cultivated in blood agar chocolate medium, with the purpose of isolating bacteria and thus quantifying them. The colony numbers were multiplied by the reciprocal of the dilution and the results expressed as colony forming units per ml (CFU / $\mathrm{ml})$.

To stratify
mortality it was used the following scores: $\underline{\text { Score } 0}$ - Animals that died of septic shock in the first 24 hours after induction of fecal peritonitis;

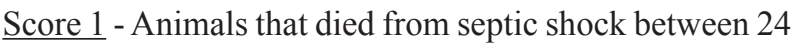
and 48 hours after induction of peritonitis;

$\underline{\text { Score } 3}$ - Animals that died between 48 hours and eight days after the induction of peritonitis, with obvious clinical signs of serious infection;

$\underline{\text { Score } 5}$ - Animals that survived until the eighth day after the induction of fecal peritonitis and were euthanized on the eighth day; however the clinics were compatible with major infection and bacterial clearance did not present in all samples;

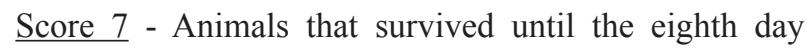
after induction of fecal peritonitis and, when evaluated by the veterinary, they showed behavior similar to healthy rats with absolutely normal clinical status. Additionally, microbiological studies of the blood and tissues collected from them showed no bacterial growth.

Quantitative parameters were expressed by their mean \pm Standard Error of the Mean (SEM); the qualitative ones were expressed by their frequencies.

Student " $\mathrm{t}$ " test was used for unpaired quantitative parameters. ANOVA test was used for quantitative parameters for more than two groups. If the test resulted in $\mathrm{p}<0.05$ ), TukeyKramer was used for identifying difference among means.

Chi-square was used for assessing association. Fisher exact test was used for assessing differences between frequencies of mature animal parameters with and without PBCL. $p<0.05$ was used for rejecting the null hypothesis.

\section{Results}

The mature rats that underwent PBCL had a mean age of $8.5 \pm 0.8$ months and weight of $461.3 \pm 15.3 \mathrm{~g}$. The animals in the young group had a mean age of $2.4 \pm 0.2$ months and mean weight of $247.7 \pm 10.5 \mathrm{~g}$. The mature animals without PBCL presented mean age of $15.5 \pm 0.2$ months and mean weight of $474.2 \pm 23.6$ g. The mean age of mature animals with and without PBCL were significantly higher than the younger group ( $p<0.0001)$. It was observed that the mean age was significantly higher in the rats with PBCL compared with those without PBCL $(\mathrm{p}<0.001)$.

There was no significant difference between the mean weights of the mature groups with and without PBCL $(p=0.859)$, although differences were observed in comparisons between young and mature undergoing PBCL $(\mathrm{p}<0.001)$.

When observing the variation in weight between the time of inoculation and immediately before the animal death, it is found that there was a statistically significant weight loss in rats subjected to PBCL $(p=0.005)$. An increase of the mean weights of the young rats $(p=0.016)$, even after induction of autogenous peritonitis. There was no difference in the pairing of the mean weights of mature rats without PBCL regarding different moments; autogenous induction of fecal peritonitis and death $(p=0.326)$.

TABLE 1 - Rat weight means at different times; before fecal induction and prior to euthanasia.

\begin{tabular}{c|c|c|c|}
\hline \multirow{2}{*}{ Weight } & \multicolumn{3}{|c|}{ Groups (mean \pm SD) } \\
\cline { 2 - 4 } & $\begin{array}{c}\text { Mature } \\
\text { with PBCL }\end{array}$ & Young & $\begin{array}{c}\text { Mature } \\
\text { without } \\
\text { PBCL }\end{array}$ \\
\hline Before & $461.3 \pm 15.3$ & $247.7 \pm 10.5$ & $474.2 \pm 23.6$ \\
Death time & $408.4 \pm 11.6$ & $271.6 \pm 10.8$ & $476.4 \pm 23.8$ \\
p-value & 0.005 & 0.016 & 0.326 \\
\hline
\end{tabular}

When considering microbiological investigation from the peritoneum samples, four rats without PBCL were positive, while one rat with $\mathrm{PBCL}$ presented positive microbe growth (Tables 2 and 3)

Regarding the lungs four rats without PBCL had bacterial 
growth while three rats with PBLC had positive cultures (Tables 2 and 3$)$.

Positive bacterial identification in blood samples taken from the carotid artery (blood 1) it was observed in five rats with PBCL and six without PBCL. In blood taken from the right heart (blood 2) there was bacterial growth are five rats with PBCL and five animals without PBCL. In one young rat bacterial growth was present in the blood sample taken from the right heart (Tables 2 and 4).

TABLE 2 - Frequency distribution for the presence of bacteria in the peritoneum, lung and blood in relation to the studied groups.

\begin{tabular}{|c|c|c|c|}
\hline & \multicolumn{3}{|c|}{ Groups (n----\%) } \\
\hline & PBCL & Young & Without PBCL \\
\hline Peritoneum & 110.0 & --- & $4 \quad 40.0$ \\
\hline Lung & 330.0 & --- & $4 \quad 40.0$ \\
\hline Blood 1 & $5 \quad 50.0$ & --- & $6 \quad 60.0$ \\
\hline Blood 2 & $5 \quad 50.0$ & $1 \quad 10.0$ & 50.0 \\
\hline
\end{tabular}

TABLE 3 - Bacterial diversity from fragments of peritoneum and lung.

\begin{tabular}{|c|c|c|c|c|c|c|}
\hline \multirow[b]{2}{*}{ Bacteria } & \multicolumn{3}{|c|}{ Peritoneum (n) } & \multicolumn{3}{|c|}{ Lung (n) } \\
\hline & PBCL & Young & $\begin{array}{l}\text { Without } \\
\text { PBCL }\end{array}$ & PBCL & Young & $\begin{array}{c}\text { Without } \\
\text { PBCL }\end{array}$ \\
\hline $\begin{array}{c}\text { Escherichia } \\
\text { coli }\end{array}$ & 1 & - & 4 & 1 & - & 3 \\
\hline $\begin{array}{c}\text { Klebsiella } \\
\text { pneumoniae }\end{array}$ & - & - & 1 & 2 & - & 1 \\
\hline $\begin{array}{l}\text { Pseudomonas } \\
\text { aeruginosa }\end{array}$ & - & - & 2 & 2 & - & - \\
\hline $\begin{array}{c}\text { Enterococcus } \\
\text { faecalis }\end{array}$ & - & - & 1 & - & - & 2 \\
\hline $\begin{array}{c}\text { Staphylococcus } \\
\text { epidermidis }\end{array}$ & - & - & - & - & - & - \\
\hline $\begin{array}{l}\text { Streptococcus } \\
\text { viridans }\end{array}$ & - & - & - & - & - & - \\
\hline $\begin{array}{l}\text { Proteus } \\
\text { mirabilis }\end{array}$ & - & - & 3 & 1 & - & - \\
\hline
\end{tabular}

TABLE 4 - Bacterial diversity from blood microbiology (carotid and right ventricle).

\begin{tabular}{c|c|c|c|c|c|c}
\hline \multirow{2}{*}{ Bacteria } & \multicolumn{3}{|c|}{ Blood - Carotid (n) } & \multicolumn{3}{c}{$\begin{array}{c}\text { Blood- right } \\
\text { ventricle (n) }\end{array}$} \\
\cline { 2 - 6 } & PBCL & Young & $\begin{array}{c}\text { Without } \\
\text { PBCL }\end{array}$ & PBCL & Young & $\begin{array}{c}\text { Without } \\
\text { PBCL }\end{array}$ \\
\hline $\begin{array}{c}\text { Escherichia } \\
\text { coli }\end{array}$ & 1 & - & 4 & 1 & - & 3 \\
$\begin{array}{c}\text { Klebsiella } \\
\text { pneumoniae }\end{array}$ & - & - & 1 & - & - & 1 \\
$\begin{array}{c}\text { Klebsiella } \\
\text { oxytoca }\end{array}$ & - & - & - & - & 1 & - \\
$\begin{array}{c}\text { Pseudomonas } \\
\text { aeuruginosa }\end{array}$ & 1 & - & 1 & 1 & - & 1 \\
$\begin{array}{c}\text { Enterococcus } \\
\text { faecalis }\end{array}$ & 2 & - & 1 & 2 & - & 1 \\
$\begin{array}{c}\text { Staphylococcus } \\
\text { epidermidis }\end{array}$ & 1 & - & - & 2 & - & - \\
$\begin{array}{c}\text { Streptococcus } \\
\text { viridans }\end{array}$ & 1 & - & 1 & - & - & 1 \\
$\begin{array}{c}\text { Proteus } \\
\text { mirabilis }\end{array}$ & - & - & 1 & - & - & 1 \\
\hline
\end{tabular}

In collecting the peritoneum fragment it was observed signs of previous infectious process or activity (abscesses and adhesions in the abdominal cavity) (Table 5). These processes were less evident in young control rats $(\mathrm{p}<0.001)$. There was no statistically significant difference $(\mathrm{p}=1.000)$ between the mature groups with and without PBCL.

TABLE 5 - Distribution of frequencies for the presence of gross lesions (abscesses and adhesions in the abdominal cavity) in the studied groups.

\begin{tabular}{|c|c|c|c|c|}
\hline \multirow{2}{*}{$\begin{array}{l}\text { Macroscopic } \\
\text { lesions }\end{array}$} & \multicolumn{4}{|c|}{ Groups (n----\%) } \\
\hline & PBCL & Young & & $\begin{array}{l}\text { thout } \\
\text { BCL }\end{array}$ \\
\hline Present & $8 \quad 80 \%$ & ---- & 9 & $90 \%$ \\
\hline Absent & $2 \quad 20 \%$ & $10100 \%$ & 1 & $10 \%$ \\
\hline
\end{tabular}

Several animals from the mature group with PBCL had adhesions of the bowel to the peritoneum, including the parietal (Figure 1). 


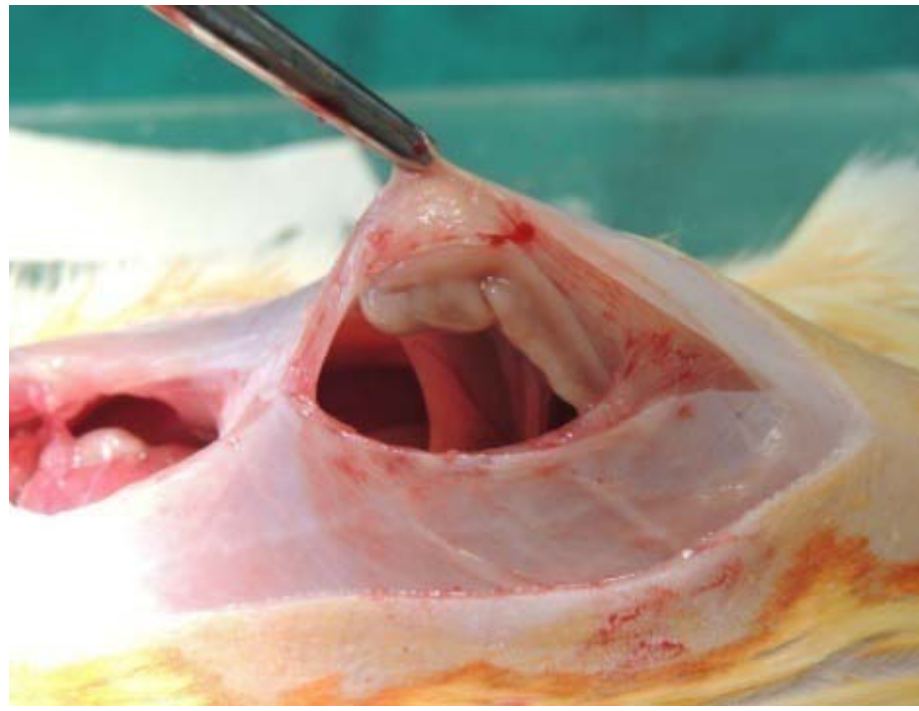

FIGURE 1 - Intestinal adhesions with the parietal peritoneum.

Among the mature animals with and without PBCL it was observed macroscopic changes related to the formation of abscesses (Figure 2).

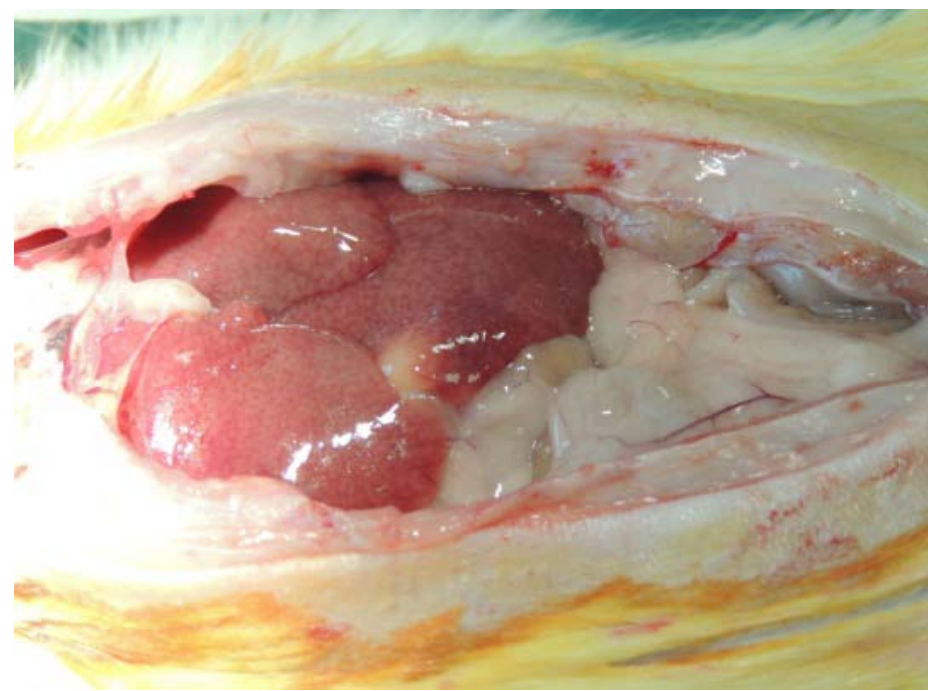

FIGURE 2 - Micro-abscesses and abscess collection in mature rat liver subjected to PBCL.

At the time of blood collection in the carotid arteries was observed that most of these arteries had hardened up like pale cords and bloodless inside, accordingly to obtain the carotid cord was dissected until the subclavian where blood samples were harvested. Additionally, it was observed adaptive arterial network of small vessels that roamed near the carotid or directly linked to its sheetor closer or farther away from the trachea heading for the brain (Figure 3).

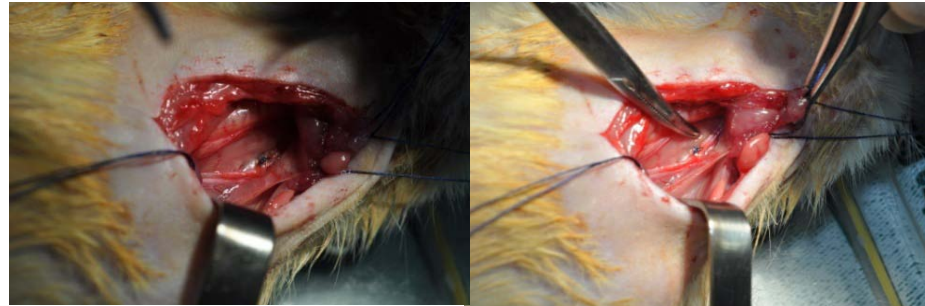

FIGURE 3 - A. Carotid occlusion with visible knot and adaptive arterial networkrunning for the encephalon. B. Carotid occlusion with visible knot and adaptive arterial vessel close to carotid adventitia.

When evaluating the survival curve one can observe that there is a statistically significant difference detected by the Log-rank test $(p=0.024)$ between the proportion of survival in the three groups. However there was no significant difference in mortality between mature rats with and without mature PBCL ( $p$ $=0.129)$ (Figure 4).

\section{Survival proportion: Survival of three groups}

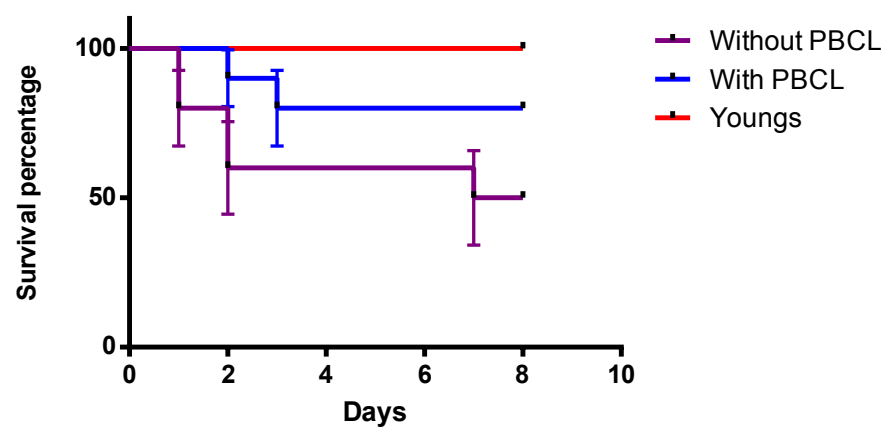

FIGURA 4 - Kaplan-Meier survival curve for the three groups.

The mean score of morbidity and mortality from the rats without PBCL was $4.8 \pm 0.4$, and with PBCL was $3.8 \pm 0.5$, while the in the young group was $6.8 \pm 0.2$. When applying the ANOVA test is observed statistically significant difference between groups $\mathrm{p}<0.001$. The Tukey-Kramer multiple comparison shows that there is a significant difference when comparing the young and mature groups with and without PBCL $(\mathrm{p}<0.001 \mathrm{q}=5.927)(\mathrm{p}<0.001 \mathrm{q}=$ $8.621)$. The comparison between groups mature groups there was no difference with or without PBCL ( $>0.05 \mathrm{q}=2.694$ ). (ANOVA $\mathrm{p}=<0.001$ - young group $-6.8 \pm 0.2$ versus with PBCL $-4.8 \pm 0.4$ $-\mathrm{q}=5.927-\mathrm{p}<0.001)$; young group $-6.8 \pm 0.2$ versus without PBCL- $3.8 \pm 0.5-\mathrm{q}=8.621-\mathrm{p}<0.001$ ); (Group with PBCL - 4.8 \pm 0.4 versus Without PBCL $-3.8 \pm 0.5-\mathrm{q}=2.694-\mathrm{p}>0.05$ ) (Figures 5 and 6). 
Morbidity and mortality score

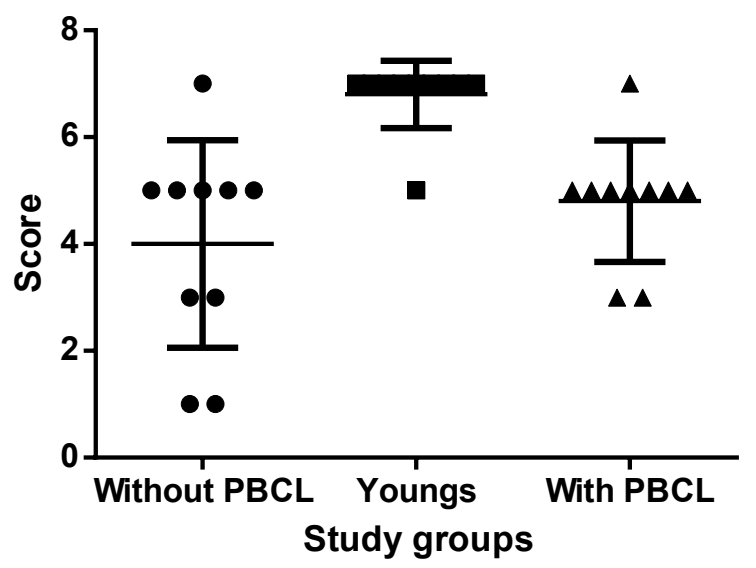

FIGURE 5 - Scatter plot of the morbidity scores.

\section{Confidence interval 95\% (Tukey)}

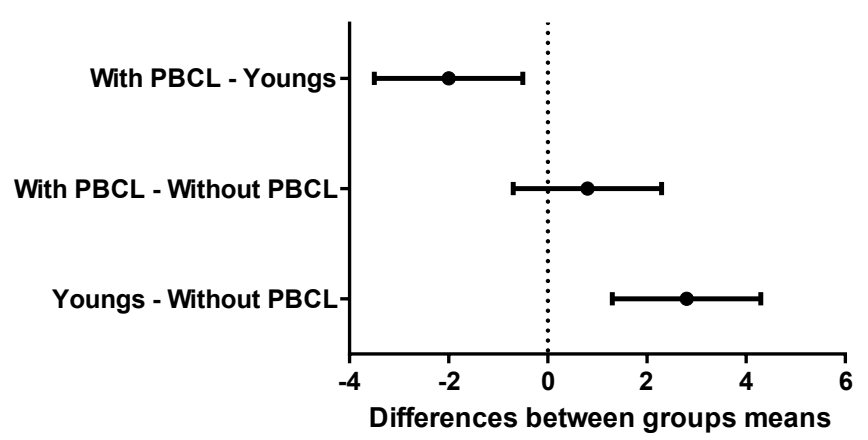

FIGURE 6 - Confidence intervals of the mean probability scores for morbidity among the rat groups.

\section{Discussion}

More than 750.000 cases of sepsis occur worldwide each year, resulting from various etiologies, including peritonitis. The mortality from this disease is between $20 \%$ and $30 \%$, even taking into account the advances in intensive care in the last two decades ${ }^{1}$.

Sepsis induces a systemic response with a significant increase of pro and anti inflammatory cytokines, well as the variation in the phenotype of the effector cells during critical illness. With the sepsis worsening, septic shock comes and there is activation of host effectors cells in response to lipopolysaccharide (LPS) and endotoxins, which are components of the cell membrane of gram-negative bacteria ${ }^{16}$.

Recognition of LPS by Toll-like receptors on the surface of macrophages permits their sensitizations consequent stimulation of the innate immune response to microbial invasion. At the same time, however LPS may signal to an exaggerated inflammatory response of the immune system, initiating an uncontrollable inflammatory response, which can lead to multiple organ failure and finally death ${ }^{16,17}$.

In humans, the infection often causes morbidity and mortalidade ${ }^{2,18}$. The purulent material found in the abdominal cavity is polymicrobial. In animal model of peritonitis is useful to study the development of disease and septicemia resulting in terms of microbiological, immunological and therapeutic forms. The material inoculated into the abdominal cavity may come from own feces or bowel segments ${ }^{12}$.

Currently, induction of peritonitis can be done in several ways including the introduction of LPS into the peritoneal cavity, fecal suspension or several microorganisms including E. coli and B. fragilis ${ }^{12,19}$.

Peritoneal abscesses are formed from infected fluid collection, encapsulated by fibrinous exudates, omentum and / or adjacent visceral organs. Most abscesses develop due to secondary peritonitis. The incidence of abscess formation after abdominal surgery is less than $1.2 \%$. The risk increases to 10 $30 \%$ in cases of drilling handles, fecal contamination significant ischemia, delay in diagnosis and therapy, as well as the existence of immunosuppressant. The abscess formation is a major cause of persistent infection and the development of septicemia. The participation of anaerobic bacteria is fundamental ${ }^{19,20}$. In this study, an experimental model was used to induce peritonitis. It demonstrated a significant increase in the number of macroscopic changes (adhesions and abscesses) in mature rats with and without PBCL, when compared to young animals. Microbiological analysis showed similar results among mature animals with and without PBCL.

Age has a direct effect on the immune response. Traditionally, cross-sectional studies in industrialized countries are unanimous in documenting the number and / or lower proportion of CD8 + T cells with advancing age, whereas the effects on CD4 $+\mathrm{T}$ cells remain unclear. Conversely, $\mathrm{CD} 8+\mathrm{T}$ cell memory are more numerous in the elderly. The greatest susceptibility to new infections in elderly compared with young subjects may reflect the lower availability of cells recognizers of new antigens. These factors may have been responsible for lower morbidity and mortality found the group in of young rats, in contrast with the mature animals with and without PBCL ${ }^{1,21,22}$.

There was no difference when compared morbidity scores of mature animals with and without PBCL. It should be emphasized that the animals that undergone peritonitis had PBCL four months prior to induction of the infection. The cognitive results show that these animals developed an adaptation to initial reduced blood flow in the brain, which can be explained by vasodilatation 
of accessory arterial brain inflow, neuronal plasticity, neurogenesis and adaptive arteriogenesis. These factors probably contributed to the recovery of neurocognitive response and ultimately to the improvement of cognitive and immune senescence, supporting the microbiological results, morbidity and mortality similar to animals that did not undergo PBCL.

Although the association between peritonitis and septicemia is not completely elucidated, during acute phase the host recognizes microorganisms and LPS that bind to proteins that have CD4 on the surface of monocytes, macrophages and neutrophils. This phenomenon induces the production and release of mediators such as TNF and interleukins $\mathrm{C} 1, \mathrm{C} 3$ and $\mathrm{C} 8$, generating amplification of the response to LPS and activating various cells responsible for innate and adaptive immune response.At the same time, occurs releasing factors derived from phospholipids, coagulation factors, complement increased activity, increased vascular permeability and endothelial production of free radicals, including nitric oxide. It should be noted the resistance of peritoneal infection through the activation of complement factors C3 and C4 from mast cells, TNF and immunoglobulin $\mathrm{M}^{5,22}$.

In medical practice, taking the gastro-intestinal perforation as precipitating event of peritonitis, the number and types of microorganisms isolated from the peritoneal cavity depend on the site of perforation. As regard to colon perforation, initially a large number of different species from enteric normal flora entering the peritoneal cavity. $B$. fragilis is the most frequent anaerobic colonic microrganism, and E. coli is the most isolated facultative anaerobic ${ }^{18}$

In rodents, the sequence of events that occur following contamination of the peritoneum with fecal flora, E. coli was responsible for sepsis and mortality in acute peritonitis while $B$. fragilis, E. coli and other microorganisms; and Enterococcus sp polymicrobial infections were responsible for the late formation of abscessos ${ }^{11,13}$.

In this research it was detected typical colonic polymicrobial flora, with no discrepancy with findings in other studies in which there was a similar induction of fecal peritonitis in rats. In this sample the mature animals with and without PBCL not survived the acute phase of the disease and were euthanized within 72 hours, were positive in some culture (peritoneum, lung, and blood) to E. coli and other microbial agents. The animals of group ripe with and without PBCL who survived until the eighth day had a higher incidence of macroscopic changes, especially abscess formation and adhesions, and polymicrobial profile the results of various cultures ${ }^{11-14}$

The relationship between acute peritonitis and E. coli, and polymicrobial infection and development of adhesions and abscesses in late stages is described in other studies, configuring important information to guide treatment in the early stages of the disease ${ }^{18,19}$.

The same types of pathogens are isolated in patients with immune deficiency and comorbidities, however, these individuals are most commonly associated with Enterococcus sp and Staplylococcus coagulase-negative. P. aeruginosa is also associated with nosocomial infection, but has been isolated in about $24 \%$ of patients with perforated appendicitis acquired comunidade. In experimental animal models of peritonitis caused by $P$. aeruginosa in rodents which has been developed aiming of understanding the pathophysiology and evaluate ways to intervene in this type of infection ${ }^{23,24}$.

Evaluating the results of the present investigation, bacterial clearance was observed virtually in all young animals that survived until the eighth day, even without the observation of macroscopic signs of infection in the peritoneal cavity. The morbidity and mortality scores were significantly higher in young animals compared with mature animals with and without PBCL, leading us to assert that age was an independent good predictor for these outcomes.

The initial hypothesis was that PBCL of rats was accompanied by decreased supply of oxygen to the brain, particularly for the hippocampus and cerebral cortex. This phenomenon is associated with loss of neurons, and consequently changes in the cognitive activity of these animals, which was proven with the follow-up of 30 days. However, after mean follow-up of four months the cognitive testing, both aquatic and terrestrial, indicated the return of normal cognitive activity. The explanation for these findings are based on evidence that disability oxygen to the brain due to PBCL is compensated by adaptive three phenomena: activation of neuronal plasticity with creation of new synapses and neurogenesis; besides hemodynamic adaptation by both arteriogenesis ${ }^{25}$, as well as by the vasodilation of arterial blood flow from the posterior tributaries, branches of the vertebral arteries, which can also contribute to irrigation of the brain in these animals. This adaptation in response to hemodynamic PBCL includes spontaneous improvement of cognitive functions on long term follow-up. Thus, this model of cerebral ischemia for investigation of the cognitive responses and their impact cannot be considered suitable for implementation in humans.

The second hypothesis was that rats undergoing PBCL could present deficient immune response upon challenge autogenous fecal peritonitis and consequent septicemia. The results support the hypothesis that the PBCL procedure, with the 
follow-up period of four months, does not interfere in morbidity or mortality, comparable to healthy rats without this procedure. However, it should be noted that the rats with PBCL presented with average age lower than healthy rats without surgery. So, there was a tendency to better immune response in this group. The data support the hypothesis that the immune response of rats to fecal peritonitis has age as an independent predictor.

\section{Conclusions}

1. The immune response to fecal peritonitis in healthy young rats was significantly more efficient than that of mature rats both with and without PBCL, reflected in lower morbidity and mortality;

2. The morbidity and mortality from peritonitis and sepsis were greater in mature rats, yet similar between rats with and without PBCL.

3. The microbiology of pre-lung (heart right ventricle), post-lung (carotid) arterial blood, peritoneum and lung in mature rats with and without PBCL reflects the diversity of gram-negative microorganisms constituting the colonic flora.

\section{References}

1. Iwashyna TJ, Cooke CR, Wunsch H, Kahn JM. Population burden of long-term survivorship after severe sepsis in older Americans.J Am Geriatr Soc. 2012;60(6):1070-7.

2. Weiss G, Steffanie W, Lippert H. Peritonitis: main reason of severe sepsis in surgical intensive care. ZentralblChir. 2007;132(2):130-7.

3. Curcio JD. Antibiotic prescriptions in intensive care units in Latin America. Rev Arg Microbiol. 2011;43:2003-11.

4. Soares MO, Welton NJ, Harrison DA, Peura P, Shankar- Hari M, Harvey SE, Madan JJ, Ades AE, Palmer SJ, Rowan KM. An evaluation of the feasibility, cost and value of information of a multicentrerandomised controlled trial of intravenous immunoglobulin for sepsis (severe sepsis and septic shock): incorporating a systematic review, meta-analysis and value of information analysis. Health Technol Assess. 2012;16(7):1-186.

5. Aziz M, Jacob A, Yang WL, Matsuda A, Wang P. Current trends in inflammatory and immunomodulatory mediators in sepsis. J Leukoc Biol. 2013;93(3):329-42.

6. Katayama Y, Terashi A, Sugimoto S, Inamura K, Suzuki S, Sekiguchi F, Akashi A. Experimental cerebral ischemia after bilateral common carotid artery ligation in SHRSP, SHRSR and Wistar rats: correlation between blood pressure and degree of ischemia. No To Shinkei. 1984;36(11):1069-75.

7. Tsuchiya M, Sako K, Yura S, Yonemasu Y. Cerebral blood flow and histopathological changes following permanent bilateral carotid artery ligation in Wistar rats. Exp Brain Res. 1992;89(1):87-92.

8. Aw D, Silva AB, Palmer DB: Immunosenescence: emerging challenges for an ageing population. Immunology. 2007;120:43546.

9. Ziaja M. Sepsis and septic encephalopathy: characteristics and experimental models. Folia Neuropathol. 2012;50(3):231-9.

10. Ehrnthaller C, Amara U, Weckbach S, Kalbitz M, Huber-Lang M, Bahrami S. Alteration of complement hemolytic activity in different trauma and sepsis models. J Inflamm Res. 2012;5:59-66.
11. Buyne OR, Bleichrodt RP, Verweij PE, Groenewoud HM, van Goor $\mathrm{H}$, Hendriks T. A peritonitis model with low mortality and persisting intra-abdominal abscesses. Int J ExpPathol. 2006;87(5):361-8.

12. Kreimer F, Aguiar JLA, Castro CMMB, Lacerda CM, Reis T, Lisboa Junior F. Respostaterapêutica e inflamatória de ratos com peritonitesecundáriasubmetidosaousotópico de ampicilina/ sulbactam. Acta Cir Bras. 2005;20:31-9.

13. Gonnert FA, Recknagel P, Seidel M, Jbeily N, Dahlke K, Bockmeyer CL, Winning J, Lösche W, Claus RA, Bauer M. Characteristics of clinical sepsis reflected in a reliable and reproducible rodent sepsis model. J Surg Res. 2011;170:e123-34.

14. Weinstein WM, Onderdonk AB, Bartlett JG, Gorbach SL. Experimental intra-abdominal abscesses in rats: development of an experimental model. Infect Immun. 1974;10(6):1250-5.

15. Okazaki Y, Matsukawa A. Pathophysiology of sepsis and recent patents on the diagnosis, treatment and prophylaxis for sepsis. Recent Pat Inflamm Allergy Drug Discov. 2009;3(1):26-32.

16. Chiang N, Fredman G, Bäckhed F, Oh SF, Vickery T, Schmidt BA, Serhan CN. Infection regulates pro-resolving mediators that lower antibiotic requirements. Nature. 2012;484:524-8.

17. Giacometti A, Silvestri C, Oscar Cirioni O, Bozzi A, Barra D, Ghiselli R, Di Giulio A, Saba V, Mocchegiani F, Scalise G, Luzi C, Orlando F, Mangoni ML, Rinaldi AC. Interaction of antimicrobial peptide temporin $\mathrm{L}$ with lipopolysaccharide in vitro and in experimental rat models of septic shock caused by gram-negative bacteria. Antimicrobiol Agents Chemother. 2006;50(7): 2478-86.

18. Fieren MW. The local inflammatory responses to infection of the peritoneal cavity in humans: their regulation by cytokines, macrophages, and other leukocytes. Mediators Inflamm. 2012;2012:976241.

19. Gorbach SL, Bartlett JG. Anaerobic infections. 1. N Engl J Med. 1974;290(21):1177-84.

20. Moreno SE, Alves-Filho JC, Alfaya TM, da Silva JS, Ferreira SH, Liew FY. IL-12, but not IL-18, is critical to neutrophil activation and resistance to polymicrobial sepsis induced by cecal ligation and puncture. J Immunol. 2006;177:3218-24.

21. Gruver AL, Hudson LL, Sempowski GD. Immunosenescence of ageing. J Pathol. 2007;211:144-56.

22. Bosshart H, Heinzelmann M. Targeting bacterial endotoxin: two sides of a coin. Ann N Y Acad Sci. 2007;1096:1-17.

23. Michéa-Hamzehpour M, Auckenthaler R, Regamey P, Pechère JC. Resistance occurring after fluoroquinolone therapy of experimental Pseudomonas aeruginosa peritonitis. Antimicrob Agents Chemother. 1987;31(11):1803-8.

24. Watanabe R, Matsumoto T, Sano G, Ishii Y, Tateda K, Sumiyama Y, Uchiyama J, Sakurai S, Matsuzaki S, Imai S, Yamaguchi K. Efficacy of bacteriophage therapy against gut-derived sepsis caused by Pseudomonas aeruginosa in mice. Antimicrob Agents Chemother. 2007;51:446-52.

25. Busch HJ, Buschmann IR, Mies G, Bode C, Hossmann KA. Arteriogenesis in hypoperfused rat brain. J Cereb Blood Flow Metab. 2003;23(5):621-8

\section{Correspondence:}

Carlos Teixeira Brandt

Avenida Boa Viagem, 5030/1302

51011-000 Recife - PE Brasil

Tel.: (55 81)3342-0830

carlosbrandt@,bol.com.br

Received: December 18, 2012

Review: February 20, 2013

Accepted: March 19, 2013

Conflict of interest: none

Financial source: Medical Sciences, Faculty of Campina Grande

${ }^{1}$ Research performed at Experimental Research Unit, Medical Sciences, Faculty of Campina Grande (FCM), Paraiba, Brazil. Part of PhD degree thesis, Postgraduate Program in Surgery, Federal University of Pernambuco (UFPE). Tutor: Prof. Carlos Teixeira Brandt. 